\title{
RESEARCH
}

Open Access

\section{Evaluation of metastatic lymph nodes in cN0 thoracic esophageal cancer patients with inconsistent pathological lymph node diagnosis}

Akiyuki Wakita, Satoru Motoyama, Yusuke Sato, Yuta Kawakita, Yushi Nagaki, Kaori Terata, Kazuhiro Imai and Yoshihiro Minamiya

\begin{abstract}
Background: Preoperative clinical diagnosis of lymph node (LN) metastasis and subsequent pathological diagnosis are often not in agreement. Detection of false-negative LNs is essential in selecting an optimal treatment strategy, and most importantly, the presence of false-negative LN is itself a significant prognostic indicator. Therefore, at present, there is an urgent need to establish more accurate and individualized evaluation methods for LN metastasis.

Methods: Of 213 cNO patients who underwent curative esophagectomy without preoperative neoadjuvant treatment, 60 (28\%) had LN metastasis diagnosed pathologically. There were 129 false-negative LNs, of which 85 were detectable by preoperative computed tomography $(C T)$. We retrospectively investigated the distribution, frequency, and characteristics of pathologically positive nodes in patients with clinically NO esophageal cancer.

Results: The paracardial region was the most frequent region of false-negative LNs, accounting for $26 \%$ (22 LNs) of the total incidence. False-negative LNs distributed widely from the neck to the abdomen in patients with a primary tumor in the middle thoracic esophagus. In patients with a primary tumor in the lower thoracic esophagus, four falsenegative LNs were detected in the superior mediastinum. When the short-axis diameter, shape, and attenuation patterns of the LNs were used as criteria for metastasis diagnosis, they were insufficient for an accurate diagnosis. However, false-negative LNs in the most frequently occurring sites are characterized by smaller short-axis, suggesting that accurate diagnosis cannot be made unless the diagnostic criteria for the short-axis are reduced in addition to shape and attenuation.
\end{abstract}

Conclusions: Although restrictive to the most frequent regions of false-negative LNs occur, reducing size criterion and consideration of their shape and attenuation may contribute to improved diagnosis.

Keywords: False-negative lymph node, Lymph node metastasis, Esophageal cancer

* Correspondence: wakita@gipc.akita-u.ac.jp

Department of Thoracic Surgery, Akita University Graduate School of

Medicine, 1-1-1 Hondo, Akita 010-8543, Japan

C C The Author(s). 2020 Open Access This article is licensed under a Creative Commons Attribution 4.0 International License, which permits use, sharing, adaptation, distribution and reproduction in any medium or format, as long as you give appropriate credit to the original author(s) and the source, provide a link to the Creative Commons licence, and indicate if changes were made. The images or other third party material in this article are included in the article's Creative Commons licence, unless indicated otherwise in a credit line to the material. If material is not included in the article's Creative Commons licence and your intended use is not permitted by statutory regulation or exceeds the permitted use, you will need to obtain permission directly from the copyright holder. To view a copy of this licence, visit http://creativecommons.org/licenses/by/4.0/ The Creative Commons Public Domain Dedication waiver (http://creativecommons.org/publicdomain/zero/1.0/) applies to the data made available in this article, unless otherwise stated in a credit line to the data. 


\section{Background}

Regardless of advances in the comprehensive treatment of esophageal cancer, overall survival and preoperative 5 -year survival remain poor $[1,2]$. Lymph node stage is a key independent prognostic indicator in esophageal cancer. Beyond that, both the number and specific distribution of LN metastasis have been considered significant prognostic factors [3, 4]. For superficial esophageal cancer without LN metastasis, endoscopic mucosal resection (EMR) or endoscopic submucosal dissection (ESD) has shown results comparable to esophagectomy $[5,6]$. In cases of locally advanced esophageal cancer without distant metastasis, the surgical approach and potential application of neoadjuvant therapy are dependent on the preoperative evaluation. Consequently, an accurate evaluation to identify those patients most likely to benefit from surgical intervention and those that are sufficient with minimally invasive treatment preserving esophagus is essential.

The presence of false-negative LNs hinders the actual cancer status and selection of an appropriate treatment. Despite its importance, preoperative clinical LN diagnosis and final pathological evaluation are often inconsistent [7]. In an earlier study, the rate of false-negative LN metastasis was reported to be $11-56 \%$ [8]. Clearly, a more accurate and individualized method or new criteria for conventional radiologic imaging are urgently required. To address this issue, we investigated the distribution, frequency, and characteristics of pathologically positive LNs in patients with clinically NO esophageal cancer.

\section{Methods}

\section{Patients}

Between 2003 and 2016, 613 consecutive patients with thoracic esophageal cancer received esophagectomy at Akita University Hospital. Of those, 213 patients were diagnosed with cN0 thoracic esophageal cancer and received esophagectomy with extended 3-field lymphadenectomy without preoperative neoadjuvant therapy. Pathological diagnosis of $60 \mathrm{cN} 0$ thoracic esophageal cancer patients showed positive LN metastasis. We enrolled those 60 patients in this study and retrospectively evaluated pathologically metastatic LNs and the patients' clinical outcomes. Exclusion criteria were patients clinically diagnosed with LN metastasis and patients who received preoperative neoadjuvant chemotherapy or chemoradiotherapy. Informed consent for use of CT data for analysis was obtained from all patients included in the present study.

\section{Computed tomography scanning procedure}

During the study period, we used two types of CT scanners: Discovery CT750HD or Discovery CT750HDA
(GE Healthcare Japan, Tokyo, Japan). All patients were scanned from the neck to the pelvis. CT images were obtained using the helical technique with patients in a supine position. Slices with thicknesses of $1.25 \mathrm{~mm}$ (thin slice) and $5 \mathrm{~mm}$ were obtained before and after intravenous injection of $100 \mathrm{ml}$ of non-ionic, iodinated contrast medium at $300-350 \mathrm{mg} / \mathrm{ml}$. For contrast administration, we used an automatic injector that was set to deliver the contrast medium for $60 \mathrm{~s}$. Scanning was begun at $95 \mathrm{~s}$.

\section{Clinical diagnosis of LN metastasis in CT}

Traditionally, LNs with short diameters $\geq 10 \mathrm{~mm}$ are considered to have cancer infiltration [9-11]. However, given the consistent frequency of metastatic nodes with short axes smaller than $10 \mathrm{~mm}$, we reasoned that lowering the size criteria may contribute to more accurate diagnosis. In addition, metastatic LNs reportedly tend to be round [12], so combining axial ratio and LN size would be expected to increase sensitivity [13]. In the present study, therefore, LNs were diagnosed as metastatic when the short axis diameter was $\geq 8 \mathrm{~mm}$, the shape of the node was round, and the internal density was heterogeneous. A preoperative diagnosis of LN metastasis was made by a multidisciplinary tumor board composed of gastroenterologists, surgeons, radiologists, oncologists, and pharmacists. The classification of regional LN station was made according to the Japanese Guidelines for Clinical and Pathologic Studies on Carcinoma of the Esophagus [14, 15], as presented in Table 1. Clinical TNM stage was determined according to the international Union against Cancer tumor-nodemetastasis (TMN) Classification of Malignant Tumors (seventh edition) [16].

\section{Pathological examination for LN metastasis}

For pathological examination, each LN was fixed in $20 \%$ buffered formalin, embedded in paraffin, sectioned, and stained with hematoxylin and eosin. Further investigation with immunohistochemical staining was performed for LNs that raised suspicion of cancer involvement. All dissected LNs were microscopically analyzed for metastatic disease by pathologists. Histopathological findings were classified according to the UICC TNM classification [16].

\section{Evaluation of LNs in this study}

For each false-negative LN diagnosed microscopically, one-to-one correlation was made retrospectively with preoperative CT images. Lymph nodes not visualized by preoperative $\mathrm{CT}$ were excluded from the evaluation because of inconsistency with CT-pathological correlations. Lymph node size, configuration, and CT attenuation were measured to define the features of the false-negative LNs. We also evaluated the presence of the CT angiogram sign 
Table 1 Terminology used for lymph nodes in esophageal cancer

\begin{tabular}{|c|c|}
\hline LN station No. & Location \\
\hline \multicolumn{2}{|l|}{ Neck } \\
\hline No. 100 & Superficial lymph nodes of the neck \\
\hline No. 101 & Cervical paraesophageal lymph nodes \\
\hline No. 102 & Deep cervical lymph nodes \\
\hline No. 103 & Peripharyngeal lymph nodes \\
\hline No. 104 & Supraclavicular lymph nodes \\
\hline \multicolumn{2}{|l|}{ Mediastinum } \\
\hline No. 105 & Upper thoracic paraesophageal lymph nodes \\
\hline No. 106rec & Recurrent nerve lymph nodes \\
\hline No. 106pre & Pretracheal lymph nodes \\
\hline No. 106tb & Tracheobronchial lymph nodes \\
\hline No. 107 & Subcarinal lymph nodes \\
\hline No. 108 & Middle thoracic paraesophageal lymph nodes \\
\hline No. 109 & Main bronchus lymph nodes \\
\hline No. 110 & Lower thoracic paraesophageal lymph nodes \\
\hline No. 111 & Supradiaphragmatic lymph nodes \\
\hline No. 112aoA & Anterior thoracic paraaortic lymph nodes \\
\hline No. 112aoP & Posterior thoracic paraaortic lymph nodes \\
\hline No. 112pul & Pulmonary ligament lymph nodes \\
\hline \multicolumn{2}{|l|}{ Abdomen } \\
\hline No. 1 & Right paracardial lymph nodes \\
\hline No. 2 & Left paracardial lymph nodes \\
\hline No. 3 & Lesser curvature lymph nodes \\
\hline No. 4sa & Lymph nodes along the short gastric vessels \\
\hline No. 4sb & Lymph nodes along the left gastroepiploic artery \\
\hline No. $4 d$ & Lymph nodes along the right gastroepiploic artery \\
\hline No. 5 & Suprapyloric lymph nodes \\
\hline No. 6 & Infrapyloric lymph nodes \\
\hline No. 7 & Lymph nodes along the left gastric artery \\
\hline No. $8 a$ & Lymph nodes along the common hepatic artery (anterosuperior group) \\
\hline No. $8 p$ & Lymph nodes along the common hepatic artery (posterior group) \\
\hline No. 9 & Lymph nodes along the celiac artery \\
\hline No. 10 & Lymph nodes at the splenic hilum \\
\hline No. $11 p$ & Lymph nodes along the proximal splenic artery \\
\hline No. 11d & Lymph nodes along the distal splenic artery \\
\hline No. 12 & Lymph nodes in the hepatoduodenal ligament \\
\hline
\end{tabular}

The left (L) and right (R) sides are considered separately for Nos. 101, 102, 104, 106rec, and 112pul

within the lesion in both the $1.25-\mathrm{mm}$ thin slice and 5$\mathrm{mm}$ slice axial images. To determine the size and configuration of the LNs, the long and short axes were measured, and the long-to-short axis ratios were calculated. The CT attenuation values of the nodes were compared with that of muscle attenuation and classified as hyper-, iso-, or hypo-attenuating.

\section{Surgery}

Our standard operative procedure is right transthoracic or thoracoscopic esophagectomy with extended 3-field lymphadenectomy (bilateral neck including supraclavicular LN and mediastinal and abdominal lymph nodes). We commonly perform reconstruction by inserting a gastric tube via the posterior mediastinal or the retrosternal route. 


\section{Statistical analysis}

Continuous variables are presented as medians (minimum-maximum). Categorized data were analyzed using the Pearson's Chi square test or Fisher's exact probability test. All statistical analysis was performed using JMP 11 (SAS Institute Inc., Cary, NC, USA) and yielded twosided $p$ values. Values of $p<0.05$ were considered statistically significant.

\section{Results}

\section{Patient characteristics}

The patients' clinicopathological characteristics are summarized in Table 2. Of $213 \mathrm{cN} 0$ patients who underwent curative esophagectomy without neoadjuvant treatment, 60 (28\%) had total of 129 pathologically diagnosed metastatic LNs. That patient population included 51 (85\%) males and 9 (15\%) females with a median age of 67 years (range, 51-85 years). Four (7\%) of the tumors were in the upper thoracic esophagus, 33 (55\%) were in the middle thoracic segment, and $23(38 \%)$ were in the lower thoracic segment. The median tumor size was $40 \mathrm{~mm}$ (range, $10-95 \mathrm{~mm}$ ). The depth of the tumor invasion was pT1 in $29(48 \%)$ patients, T2 in $7(12 \%)$ patients, T3 in $22(37 \%)$ patients, and T4 in $2(3 \%)$ patients. Histological findings showed that in $49(82 \%)$ patients the tumor was a squamous cell carcinoma, while in $5(8 \%)$ patients it was an adenocarcinoma.

Frequency and most likely locations of false-negative LNs At total of 129 false-negative LNs were detected in 60 patients. Retrospectively examined, 85 (66\%) of the LNs were visualized in the preoperative enhanced CT. Their distribution is summarized in Fig. 1. Sixteen (18.8\%) false-negative LNs were detected in the right paracardial region. This was followed in descending order by the lesser curvature LNs $(15 / 85,17.6 \%)$, left recurrent nerve LNs $(10 / 85,11.8 \%)$, and right recurrent nerve LNs $(7 / 85,8.2 \%)$.

\section{Locations of false-negative LNs and the primary tumors}

The regions of false-negative LNs in patients with primary tumors in the upper, middle, or lower thoracic esophagus are summarized in Fig. 2. In patients with upper thoracic esophageal cancer, all five false-negative LNs were located within superior mediastinal region, four were left recurrent LNs, and 1 was a left tracheobronchial LN. In patients with a primary tumor in the middle thoracic esophagus, 46 false-negative LNs were widely distributed from the neck to the abdomen. In patients with a primary tumor in the lower thoracic esophagus, four of 34 falsenegative LNs were detected in the superior mediastinal region. Three were right recurrent nerve LNs, and one was a left recurrent nerve LN.
Size, shape, and attenuation values of false-negative LNs Features of false-negative LNs evaluated by CT are shown in Table 3. Understandably, 76 (89\%) of the falsenegative LNs did not exceed $8 \mathrm{~mm}$ in size. The long-toshort axis ratio was less than 2 in $73(86 \%)$ of the 85 LNs. Fifty nodes (59\%) were iso-attenuated, and 16 (19\%) were hypo-attenuated. With addition of shape (round) and attenuation (iso-hypo) to the criteria for false-negative LNs, still only $5(6 \%)$ of the 85 falsenegative LNs would be regarded as metastatic. Particularly, $50-56 \%$ of false-negative LNs in the paracardial region had short diameters less than $5 \mathrm{~mm}$ and long-toshort axis ratios of less than 2 , and they were iso-hypoattenuated (Figs. 3 and 4). Upon further addition of a reduced $\mathrm{CT}$ size criterion $(\geq 5 \mathrm{~mm})$ for false-negative LNs in the most frequent locations, 16 (30\%) of the 54 false-negative LNs would be regarded as metastatic.

\section{Discussion}

Our present study demonstrates that $28 \%$ of patients who underwent esophagectomy with LN dissection without neoadjuvant treatment had LNs falsely diagnosed as negative for metastasis, which is consistent with an earlier study [8]. False-negative LNs were most recognized in paracardial (Nos.1, 2) and paratracheal (No.106) region. In addition, it was shown that false-negative LNs in the most frequent region were smaller than those in other regions.

Due to the complex development of the lymphatic network around the esophagus, LN metastasis of thoracic esophageal cancer widely distributes from the neck to the abdomen [17, 18]. Indeed, our study showed that false-negative LNs were not limited to the vicinity of the primary tumor. Our assessments of nodal metastasis, taking into consideration the location of primary tumor, showed that false-negative LNs associated with middle thoracic esophageal tumors distributed broadly from the neck to abdomen. Moreover, in patients with a primary tumor in the lower thoracic esophagus, false-negative LNs were detected even in the superior mediastinum. Among the various regions for possible LN metastasis, false negatives were most frequently detected among the paracardial (Nos.1, 2) and paratracheal (No.106) LNs (26\% and 22\%, respectively). Focusing on the most frequent region (paracardial; Nos.1, 2), 50-56\% of falsenegative LNs were small $(<5 \mathrm{~mm})$. This suggests that in the frequent regions of false-negative LNs, even small LNs may be metastatic when they are roundish and isohypo-attenuated. Because LN metastases are often microscopic, the cancer-involved nodes may be small, as in these cases. Kajiyama et al. reported that $37.2 \%$ of metastatic LNs were $<5 \mathrm{~mm}$ in diameter [19]. This makes diagnosis difficult at the preoperative stage. 
Table 2 Clinicopathological features of cNO esophageal cancer patients

\begin{tabular}{|c|c|c|c|}
\hline \multirow[t]{2}{*}{ All patients $(n=213)$} & \multicolumn{2}{|c|}{ Lymph node involvement } & \multirow[t]{2}{*}{$p$} \\
\hline & Positive $(n=60)$ & Negative $(n=153)$ & \\
\hline Gender & & & 0.712 \\
\hline Female & 9 & 20 & \\
\hline Male & 51 & 133 & \\
\hline Age at surgery & $67(51-85)$ & $66(39-81)$ & 0.890 \\
\hline Tumor location & & & 0.338 \\
\hline Upper & 4 & 18 & \\
\hline Middle & 33 & 79 & \\
\hline Lower & 23 & 56 & \\
\hline Tumor size (mm) & $40(10-95)$ & $35(10-106)$ & 0.146 \\
\hline Tumor depth (pT) & & & $<0.0001^{*}$ \\
\hline $\mathrm{T} 1$ & 29 & 123 & \\
\hline $\mathrm{T} 2$ & 7 & 10 & \\
\hline T3 & 22 & 18 & \\
\hline T4a & 2 & 0 & \\
\hline $\mathrm{T} 4 \mathrm{~b}$ & 0 & 2 & \\
\hline Lymph node metastasis (pN) & & & $<0.0001^{*}$ \\
\hline No & 0 & 152 & \\
\hline N1 & 45 & 0 & \\
\hline N2 & 12 & 1 & \\
\hline N3 & 3 & 0 & \\
\hline Pathological stage & & & $<0.0001^{*}$ \\
\hline $\mathrm{IA}$ & 1 & 109 & \\
\hline IB & 0 & 23 & \\
\hline$\| A$ & 0 & 18 & \\
\hline$\| B$ & 27 & 0 & \\
\hline$\| \mathrm{A}$ & 23 & 1 & \\
\hline$\| \mathrm{IIB}$ & 4 & 0 & \\
\hline IIIC & 5 & 2 & \\
\hline Tumor histology & & & $0.032^{*}$ \\
\hline Squamous cell carcinoma & 49 & 141 & \\
\hline Adenocarcinoma & 5 & 6 & \\
\hline Other & 6 & 6 & \\
\hline \multicolumn{4}{|l|}{ Tumor differentiation of SCC } \\
\hline G1 & 11 & 17 & $0.005^{*}$ \\
\hline $\mathrm{G} 2$ & 23 & 101 & \\
\hline G3 & 15 & 21 & \\
\hline N/A & 0 & 2 & \\
\hline \multicolumn{4}{|l|}{ Prognosis } \\
\hline Alive & 40 & 124 & $0.017^{*}$ \\
\hline Deceased from esophageal ca. & 10 & 7 & \\
\hline Deceased from other ca. & 0 & 4 & \\
\hline Deceased from other diseases & 10 & 18 & \\
\hline
\end{tabular}




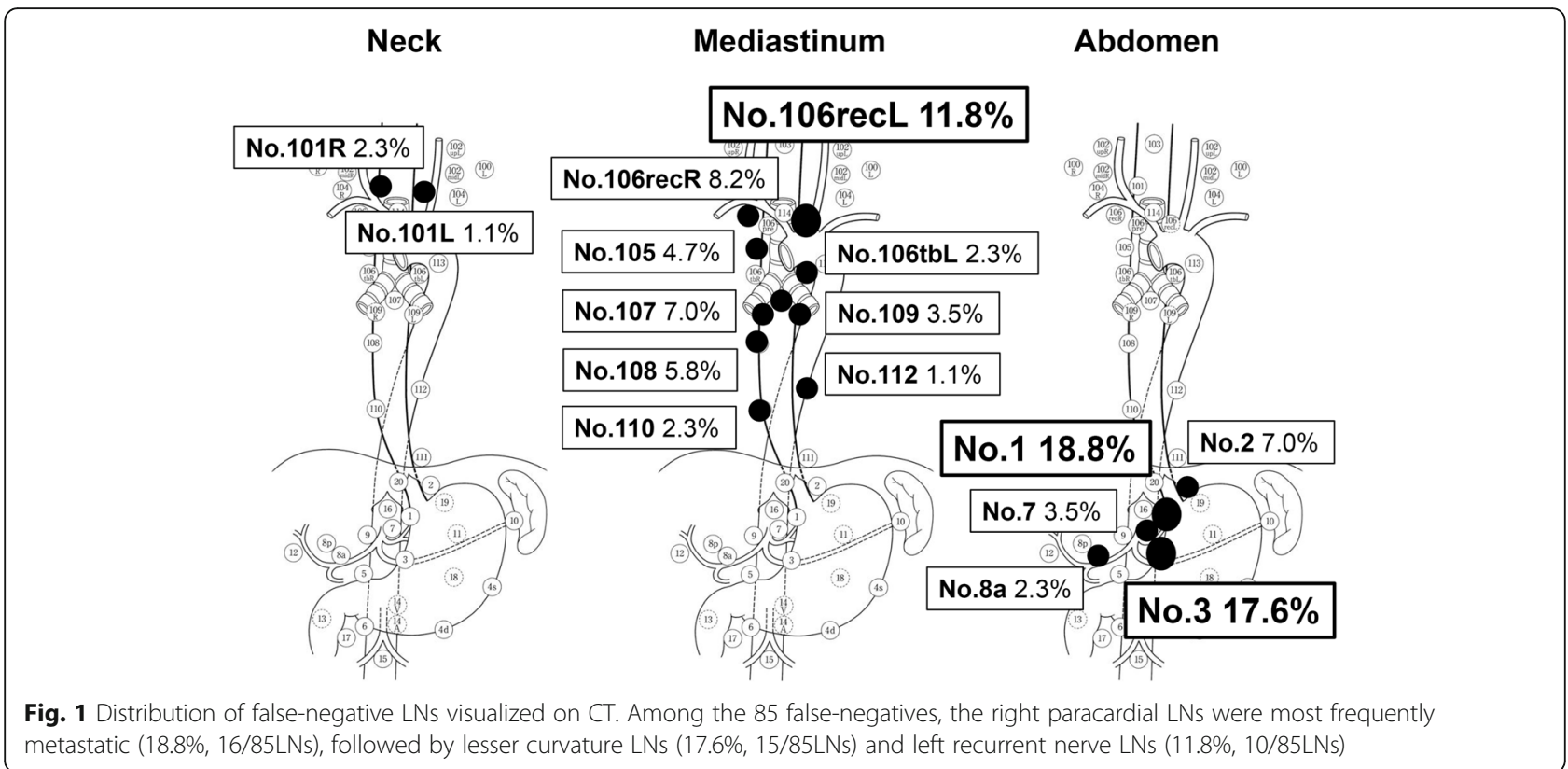

Modalities such as endoscopic ultrasound (EUS), CT, and FDG-positron emission tomography (FDG-PET) are frequently used for LN diagnosis, and previous studies report that their diagnostic performance is not satisfactory. The results of meta-analyses have shown that EUS improves the sensitivity of LN diagnosis of metastasis from 84.7 to $96.7 \%$ when combined with fine needle aspiration (FNA) [20-22] but is limited to evaluation of LNs in the proximity of the esophageal or gastric wall. FDG-PET has the disadvantage that LNs adjacent to the tumor are difficult to discriminate from the tumor itself because of poor spatial resolution. Furthermore, FGDPET is not suitable for diagnosis of small lymph node metastasis. FDG-PET has been reported to be detectable in tumors with a diameter $\geq 6 \mathrm{~mm}$ or tumors measuring $\geq 33 \mathrm{~mm}^{2}[23,24]$, making it difficult to diagnose small metastatic LNs.

CT scanning is the noninvasive and most common modality used to evaluate metastatic infiltration of LNs in esophageal cancer. Although detection of LN metastasis on CT depends primarily on the size criteria, past reports have shown that the sensitivity of $\mathrm{CT}$ is

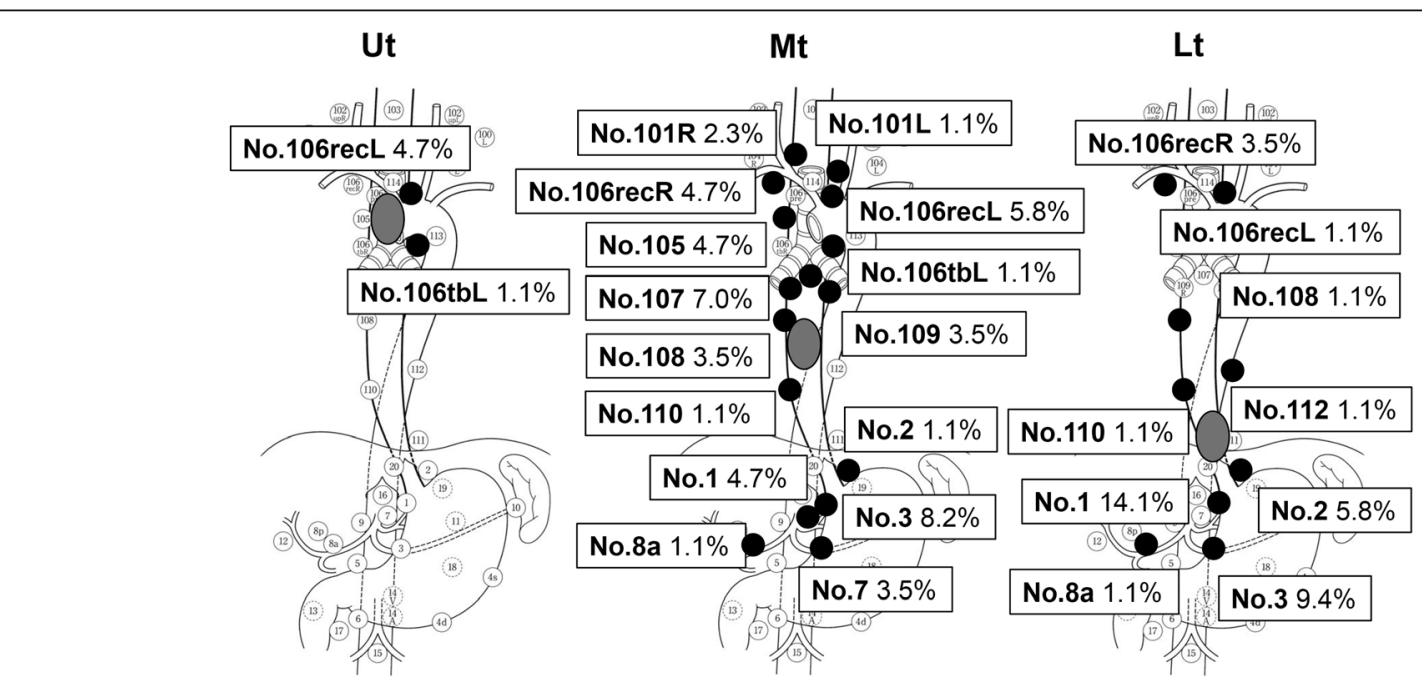

Fig. 2 Distributions of false-negative LNs and location of the primary tumors. False-negative LNs associated with upper thoracic tumors were found in the superior mediastinal region. By contrast, with middle and lower thoracic tumors, false-negative LNs were detected in all three fields 
Table 3 Features of false-negative lymph nodes evaluated by

\begin{tabular}{|c|c|c|c|}
\hline $\begin{array}{l}\text { Positive } \\
\text { for } L N \\
\text { involvement } \\
(n=85)\end{array}$ & $\operatorname{Neck}(n=3)$ & $\begin{array}{l}\text { Mediastinum } \\
(n=40)\end{array}$ & $\begin{array}{l}\text { Abdomen } \\
(n=42)\end{array}$ \\
\hline \multicolumn{4}{|l|}{ Shape of LN } \\
\hline Sphere & $1(1.2 \%)$ & $9(10.6 \%)$ & $20(23.5 \%)$ \\
\hline Oval & $2(2.4 \%)$ & $23(27.1 \%)$ & $18(21.2 \%)$ \\
\hline Flat & 0 & $8(9.4 \%)$ & $4(4.7 \%)$ \\
\hline \multicolumn{4}{|c|}{ Size (short axis) of LN (mm) } \\
\hline$\geq 10$ & 0 & $1(1.2 \%)$ & $1(1.2 \%)$ \\
\hline$<10$ & $3(3.5 \%)$ & 39 (45.9\%) & $41(48.2 \%)$ \\
\hline$\geq 8$ & 0 & $2(2.4 \%)$ & $7(8.2 \%)$ \\
\hline$<8$ & $3(3.5 \%)$ & $38(44.7 \%)$ & $35(41.2 \%)$ \\
\hline$\geq 5$ & $2(2.4 \%)$ & 19 (22.3\%) & $21(24.7 \%)$ \\
\hline$<5$ & $1(1.2 \%)$ & $21(24.7 \%)$ & $21(24.7 \%)$ \\
\hline \multicolumn{4}{|l|}{ Attenuation } \\
\hline Hypo- & 0 & $8(9.4 \%)$ & $8(9.4 \%)$ \\
\hline Iso- & $3(3.5 \%)$ & $22(25.9 \%))$ & $25(29.4 \%)$ \\
\hline Hyper- & 0 & $10(11.8 \%)$ & 9 (10.6\%) \\
\hline
\end{tabular}

unsatisfactory when LNs greater than $10 \mathrm{~mm}$ are considered positive for metastasis $[23,25,26]$. Short axis diameter alone is insufficient for detection of normally sized metastatic LNs, nor can it distinguish between reactive hyperplasia and metastatic enlargement [27]. We therefore included the shape and attenuation patterns of the nodes to verify the presence of LN metastasis. The results show that using these parameters improves detection of metastatic LNs within areas where the frequency of false-negative LNs is comparatively high.

We assume that CT scanning will continue to play a dominant role with the introduction of artificial intelligence, when not only the size, but also clinical factors such as the distribution of false-negative LNs and their frequent regions will be considered for determination of LN metastasis. However, despite the technological advances made so far, diagnosis of LN metastasis using CT remains unsatisfactory [28], and the precise role of CT for assessing disease in a preoperative setting is still under discussion.

In order to diagnose metastatic LNs more accurately, further research and establishment of other methods that supplement the limitations of diagnostic imaging are also expected. We previously reported that the CRP $1846 \mathrm{C}>\mathrm{T}$ genetic polymorphism is an independent factor associated with LN metastasis in thoracic esophageal squamous cell carcinoma. Patients carrying the CRP $1846 \mathrm{~T} / \mathrm{T}$ genotype showed LN metastasis significantly more frequently than those with other genotypes. Moreover, the specificity was $91 \%$ for cNO patients diagnosed using CT combined with CRP genetic polymorphism [29]. This combination may thus be a useful new approach to evaluating the risk of $\mathrm{LN}$ metastasis.

Our study has limitations including the nature of the retrospective study design. This study did not examine

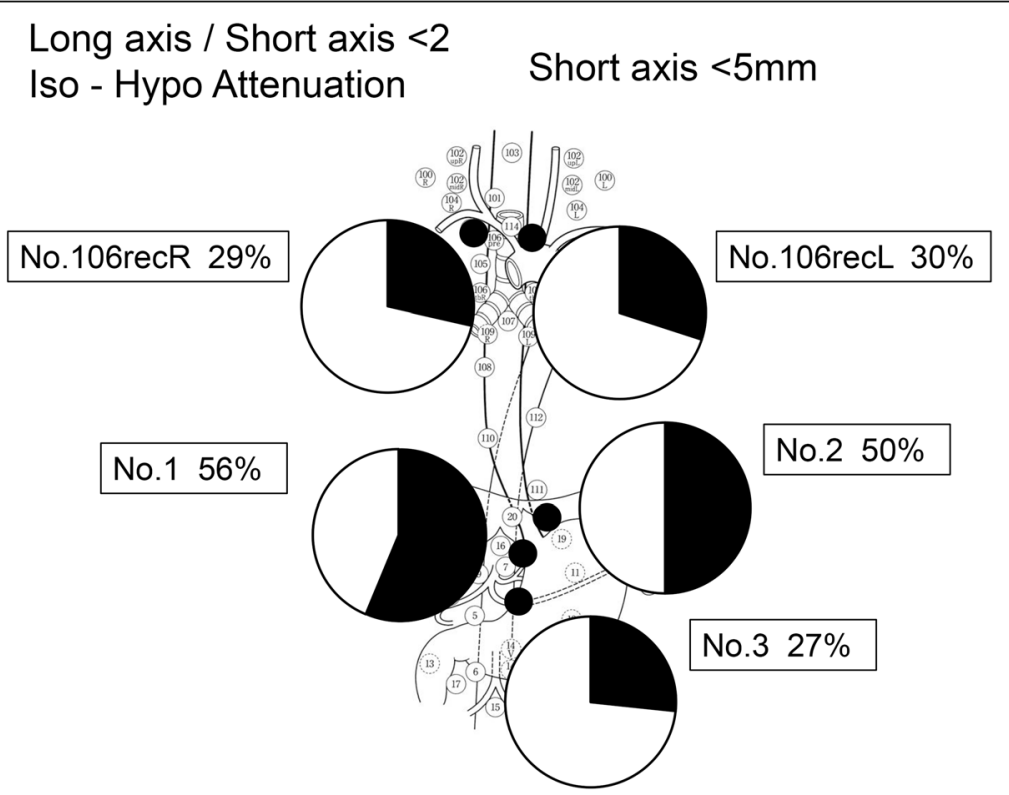

Fig. 3 Focusing on the paracardial region, where LN metastasis most frequently occurred, 50-56\% of false-negative LNs were small (<5 mm), oval, and iso-hypo attenuated. This highlights the difficulty of diagnosing LN metastasis in this region 

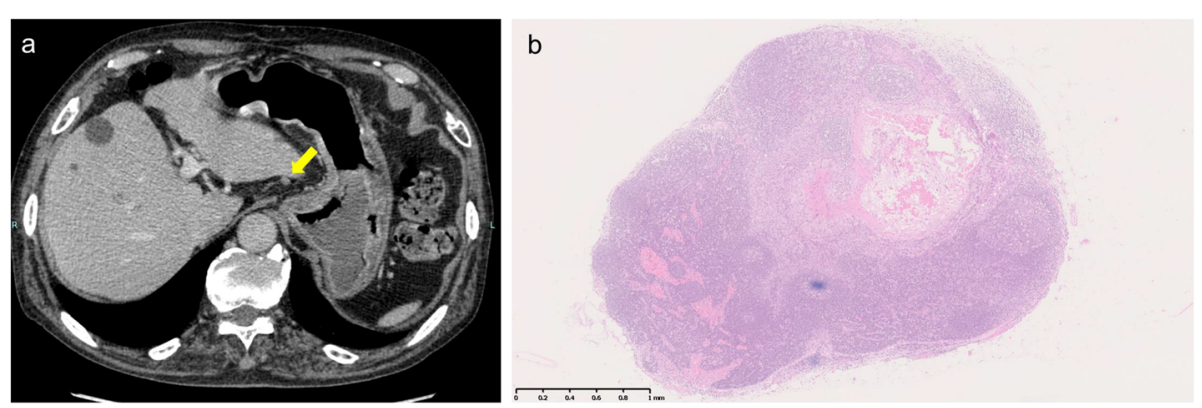

C

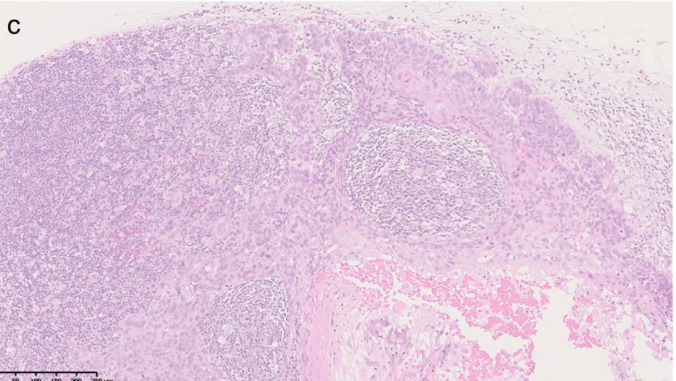

Fig. 4 Representative CT findings and microscopic findings of false-negative LN. a CT indicates iso-attenuated oval LN in paracardial region (yellow arrow). $\mathbf{b}$ The size of the LN measured $3.5 \mathrm{~mm}$ in low-magnification image. c High-magnification image shows the area of metastasis within the false-negative $L N$

all cN0 patients who were pathologically positive for LN metastasis but limited them to those who did not receive preoperative neoadjuvant therapy. This could potentially affect accurately evaluating the characteristics of falsenegative LNs.

\section{Conclusion}

In summary, the accuracy of anatomical imaging for diagnosis of LN metastasis is yet not satisfactory. Careful consideration is therefore needed, especially for diagnosis of LNs in the paracardial $($ No.1, 2) and paratracheal (No.106) regions. Limited to the most frequent regions of false-negative lymph nodes occur, reducing size criterion and consideration of their shape and attenuation may result in more accurate lymph node diagnosis.

\section{Acknowledgements}

This work was supported, in part, by Grants-in-Aid for Scientific Research from the Ministry of Education, Culture, Science, Sports and the Japan Science and Technology Agency.

\section{Authors' contributions}

Guarantors of integrity of entire study and study concepts: Wakita A, Motoyama S, and Minamiya Y; Study design or data acquisition or data analysis: Wakita A, Motoyama S, Sato Y, Kawakita Y, Nagaki Y, Terata K, Imai K: Statistical analysis and manuscript editing: Wakita A. All authors read and approved the final manuscript.

\section{Funding}

The authors have received no grant support or other forms of assistance.

\section{Availability of data and materials}

The datasets used and/or analyzed during the current study are available from the corresponding author on reasonable request.

\section{Ethics approval and consent to participate}

Informed consent for use of their clinical information in future medical research was obtained from all patients prior to surgery.

\section{Consent for publication \\ Not applicable.}

\section{Competing interests}

The authors declare that they have no competing interests.

Received: 12 February 2020 Accepted: 13 May 2020

Published online: 29 May 2020

\section{References}

1. Abnet CC, Arnold M, Wei WQ. Epidemiology of esophageal squamous cell carcinoma. Gastroenterology. 2018;154(2):360-73.

2. Tachimori Y, Ozawa S, Numasaki H, Ishihara R, Matsubara H, Muro K. et al; Registration Committee for Esophageal Cancer of the Japan Esophageal Society. Comprehensive registry of esophageal cancer in Japan, 2012. Esophagus. 2019;16(3):221-45.

3. Roder JD, Busch R, Stein HJ, Fink U, Siewert JR. Ratio of invaded to removed lymph nodes as a predictor of survival in squamous cell carcinoma of the oesophagus. Br J Surg. 1994;81(3):410-3.

4. Hosch SB, Stoecklein NH, Pichlmeier U, Rehders A, Scheunemann P, Niendorf A, et al. Esophageal cancer: the mode of lymphatic tumor cell spread and its prognostic significance. J Clin Oncol. 2001:19(7):1970-5.

5. Fujita H, Sueyoshi S, Yamana H, Shinozaki K, Toh U, Tanaka Y, et al. Optimum treatment strategy for superficial esophageal cancer: endoscopic mucosal resection versus radical esophagectomy. World J Surg. 2001;25(4): 424-31.

6. Shimizu Y, Tsukagoshi H, Fujita M, Hosokawa M, Kato M, Asaka M. Longterm outcome after endoscopic mucosal resection in patients with esophageal squamous cell carcinoma invading the muscularis mucosae or deeper. Gastrointest Endosc. 2002;56(3):387-90. 
7. Yoon YC, Lee KS, Shim YM, Kim BT, Kim K, Kim TS. Metastasis to regional lymph nodes in patients with esophageal squamous cell carcinoma: CT versus FDG PET for presurgical detection prospective study. Radiology. 2003; 227(3):764-70.

8. McGuill MJ, Byrne P, Ravi N, Reynolds J. The prognostic impact of occult lymph node metastasis in cancer of the esophagus or esophago-gastric junction: systematic review and meta-analysis. Dis Esophagus. 2008;21(3): 236-40.

9. Botet JF, Lightdale CJ, Zauber AG, Gerdes H, Winawer SJ, Urmacher C, Brennan MF. Preoperative staging of esophageal cancer: comparison of endoscopic US and dynamic CT. Radiology. 1991;181(2):419-25.

10. Takashima S, Takeuchi N, Shiozaki H, Kobayashi K, Morimoto S, Ikezoe J, et al. Carcinoma of the esophagus: CT vs MR imaging in determining resectability. AJR Am J Roentgenol. 1991;156(2):297-302.

11. Buenaventura P, Luketich JD. Surgical staging of esophageal cancer. Chest Surg Clin N Am. 2000;10(3):487-97.

12. Steinkamp HJ, Cornehl M, Hosten N, Pegios W, Vogl T, Felix R. Cervical lymphadenopathy: ratio of long- to short-axis diameter as a predictor of malignancy. Br J Radiol. 1995;68(807):266-70.

13. Liu J, Wang Z, Shao H, Qu D, Liu J, Yao L. Improving CT detection sensitivity for nodal metastases in oesophageal cancer with combination of smaller size and lymph node axial ratio. Eur Radiol. 2018;28(1):188-95.

14. Japan Esophageal Society. Japanese Classification of Esophageal Cancer, 10th edition: part I. Esophagus. 2009;6(1):1-25.

15. Japan Esophageal Society. Japanese Classification of Esophageal Cancer, 10th edition: part II-III. Esophagus. 2009;6(1):71-94.

16. Sobin LH, Gospodarowicz MK, Wittekind C, editors. TNM classification of malignant tumours International Union Against Cancer. 7th ed. Oxford, England: Wiley-Blackwell; 2009.

17. Shimada H, Okazumi S, Matsubara H, Nabeya Y, Shiratori T, Shimizu T, et al. Impact of the number and extent of positive lymph nodes in 200 patients with thoracic esophageal squamous cell carcinoma after three-field lymph node dissection. World J Surg. 2006;30(8):1441-9.

18. Xu QR, Zhuge XP, Zhang HL, Ping YM, Chen LQ. The N-classification for esophageal cancer staging: should it be based on number, distance, or extent of the lymph node metastasis? World J Surg. 2011;35(6):1303-10.

19. Kajiyama $Y$, Iwanuma $Y$, Tomita N, Amano T, Isayama F, Matsumoto T, et al. Size analysis of lymph node metastasis in esophageal cancer: diameter distribution and assessment of accuracy of preoperative diagnosis. Esophagus. 2006;3:189-95.

20. Pfau PR, Perlman SB, Stanko P, Frick TJ, Gopal DV, Said A, et al. The role and clinical value of EUS in a multimodality esophageal carcinoma staging program with $\mathrm{CT}$ and positron emission tomography. Gastrointest Endosc. 2007;65(3):377-84.

21. Puli SR, Reddy JB, Bechtold ML, Antillon D, Ibdah JA, Antillon MR. Staging accuracy of esophageal cancer by endoscopic ultrasound: a meta-analysis and systematic review. World J Gastroenterol. 2008;14(10):1479-90.

22. Pech $O$, Günter E, Dusemund F, Origer J, Lorenz D, Ell C. Accuracy of endoscopic ultrasound in preoperative staging of esophageal cancer: results from a referral center for early esophageal cancer. Endoscopy. 2010;42(6): 456-61.

23. Kato $H$, Kuwano $H$, Nakajima M, Miyazaki T, Yoshikawa M, Ojima $H$, et al. Comparison between positron emission tomography and computed tomography in the use of the assessment of esophageal carcinoma. Cancer. 2002;94(4):921-8.

24. Higuchi I, Yasuda T, Yano M, Doki Y, Miyata H, Tatsumi M, et al. Lack of fludeoxyglucose $\mathrm{F} 18$ uptake in posttreatment positron emission tomography as a significant predictor of survival after subsequent surgery in multimodality treatment for patients with locally advanced esophageal squamous cell carcinoma. J Thorac Cardiovasc Surg. 2008;136(1):205-12.

25. Kim K, Park SJ, Kim BT, Lee KS, Shim YM. Evaluation of lymph node metastases in squamous cell carcinoma of the esophagus with positron emission tomography. Ann Thorac Surg. 2001;71(1):290-4.

26. Kato H, Miyazaki T, Nakajima M, Takita J, Kimura H, Faried A, et al. The incremental effect of positron emission tomography on diagnostic accuracy in the initial staging of esophageal carcinoma. Cancer. 2005; 103(1):148-56.

27. Choi JY, Lee KH, Shim YM, Lee KS, Kim JJ, Kim SE, et al. Improved detection of individual nodal involvement in squamous cell carcinoma of the esophagus by FDG PET. J Nucl Med. 2000;41(5):808-15.
28. Yokota T, Igaki H, Kato K, Tsubosa Y, Mizusawa J, Katayama H, et al. Accuracy of preoperative diagnosis of lymph node metastasis for thoracic esophageal cancer patients from JCOG9907 trial. Int J Clin Oncol. 2016;21(2):283-8.

29. Motoyama S, Mori K, Kamei T, Miura M, Hinai Y, Sato Y, et al. Evaluation of the risk of lymph node metastasis using CRP 1846C>T genetic polymorphism in submucosal thoracic esophageal squamous cell carcinoma. Ann Surg Oncol. 2013;20(6):1978-84.

\section{Publisher's Note}

Springer Nature remains neutral with regard to jurisdictional claims in published maps and institutional affiliations.

\section{Ready to submit your research? Choose BMC and benefit from:}

- fast, convenient online submission

- thorough peer review by experienced researchers in your field

- rapid publication on acceptance

- support for research data, including large and complex data types

- gold Open Access which fosters wider collaboration and increased citations

- maximum visibility for your research: over $100 \mathrm{M}$ website views per year

At $\mathrm{BMC}$, research is always in progress.

Learn more biomedcentral.com/submissions 